\title{
Effects of blood glucose, blood lipids and blood pressure control on recovery of patients with gastric cancer complicated with metabolic syndrome after radical gastrectomy
}

\author{
LI SUN $^{1 *}$, PINGPING ZHOU ${ }^{2 *}$, QINGLI HUA ${ }^{3}$, CHANGMING JIN $^{1}$, CHUNLING GUO $^{1}$ and BING SONG ${ }^{4}$ \\ ${ }^{1}$ Department of Rehabilitation, Daqing Longnan Hospital, Daqing, Heilongjiang 163001; ${ }^{2}$ Department of Neurology, \\ Daqing Oil Field Cerebrovascular Disease Hospital, Daqing, Heilongjiang 163000; Departments of \\ ${ }^{3}$ Anesthesiology and ${ }^{4}$ Pediatrics, Daqing Longnan Hospital, Daqing, Heilongjiang 163001, P.R. China
}

Received January 18, 2018; Accepted March 16, 2018

DOI: $10.3892 /$ etm.2018.6033

\begin{abstract}
This study aimed to investigate the effects of blood glucose, blood lipids and blood pressure control on recovery of patients with gastric cancer complicated with metabolic syndrome (MS) after radical gastrectomy. A total of 150 patients with gastric cancer, who were treated in Daqing Longnan Hospital from November, 2015 to May, 2017, were enrolled in this study. The patients were divided into the MS group (80 cases) and non-MS group (70 cases). Patients in the MS group were given corresponding drugs to control blood pressure, blood lipids and blood glucose, while patients in the non-MS group were not treated with those drugs. Patients in the MS group were divided into the normal and abnormal groups according to the levels of blood glucose, blood lipids and blood pressure. Moreover, occurrences of complications were compared between the normal and abnormal groups. Before surgery, blood glucose, blood lipids and blood pressure in the MS group were significantly higher than those in the non-MS group $(\mathrm{p}<0.05)$. One month after operation, blood glucose, blood lipids and blood pressure of the MS group decreased significantly compared to those before operation $(\mathrm{p}<0.05)$. Incidence of complications at 1 and 3 months after operation was significantly lower in the normal groups than that in the corresponding abnormal groups $(\mathrm{p}<0.05)$. Postoperative recovery was significantly better in the normal groups than that in the corresponding abnormal groups $(\mathrm{p}<0.05)$. Logistic regression analysis showed that the incidence of postoperative complications was related to fasting blood glucose, $2 \mathrm{~h}$ postprandial blood glucose, glycosylated
\end{abstract}

Correspondence to: Dr Bing Song, Department of Pediatrics, Daqing Longnan Hospital, 35 Aiguo Road, Daqing, Heilongjiang 163001, P.R. China

E-mail: sbf6sd@163.com

*Contributed equally

Key words: gastric cancer, metabolic syndrome, blood glucose, blood pressure, blood lipids, postoperative complications hemoglobin, total triglycerides (TGs), LDL, mean blood pressure and BMI $(\mathrm{p}<0.05)$. The results show that, control of blood glucose, blood lipids and blood pressure in patients with gastric cancer complicated with MS after radical gastrectomy can reduce the incidence of postoperative complications and promote postoperative recovery.

\section{Introduction}

Gastric cancer is one of the most common malignant tumors of the digestive system, and the incidence of this disease ranks second among all types of cancer worldwide. Approximately 600,000 new cases are affected by gastric cancer every year worldwide, and $66 \%$ of these patients lose their lives due to this disease. The incidence of gastric cancer is two-fold higher in men than in women (1). Epidemiological studies have confirmed that gastric cancer occurs mainly in developing countries, such as China. Gastric cancer is a serious threat to human health. Therefore, in-depth studies on the mechanism of the occurrence and development of gastric cancer, as well as early detection and prevention, are extremely important for the treatment of patients with this disease (2). Related studies have shown that etiology of gastric cancer may be associated with environmental and dietary factors, and is also closely associated with Helicobacter pylori infection (3).

With the increased incidence of gastric cancer, effects of the disease-associated metabolic syndrome (MS) on the prognosis of patients with gastric cancer have been increasing. MS is a kind of syndrome with the main manifestations of central obesity, insulin resistance (IR), hypertension, high levels of triglycerides (TGs) and LDL-C, impaired glucose tolerance (IGT) and type 2 diabetes mellitus (T2DM) (4). Bloomgarden et al (5) showed that 70-80 million individuals in the United States are suffering from MS, accounting for $1 / 3$ of the total population of that country. In China, the incidence of MS is $12.25 \%$ in the southern area (6) and $11.6 \%$ in the northern area $(7,8)$, which were both lower than that in the United States, possibly due to the healthy Chinese diet and low incidence of obesity. With the changes in lifestyle, the incidence of gastric cancer has shown an increasing tendency, and gastric cancer is one of the major current health issues. 
Radical gastrectomy is currently recognized as the only way to cure gastric cancer. However, clinical application of radical gastrectomy is still challenged by the two classes of complications. The first class includes surgery-related complications, including postoperative bleeding, incision infection, incision split, lymphatic leakage, pancreatic fistula, anastomotic fistula, duodenal stump fistula, abdominal abscess, gastroparesis and intestinal obstruction. The other class includes postoperative complications, such as pneumonia, pleural effusion, cardiovascular accidents, pulmonary infarction and urinary tract infections, among which anastomotic fistula, pancreatic fistula, abdominal abscess and pneumonia are often referred to as the four major complications associated with radical gastrectomy (9).

The purpose of this study was to investigate the effects of blood glucose, blood lipid and blood pressure control on the occurrence of complications and postoperative recovery after radical gastrectomy in patients with gastric cancer complicated with MS.

\section{Materials and methods}

General information. A total of 150 patients with gastric cancer who were treated at the Daqing Longnan Hospital (Daqing, China) from November, 2015 to May, 2017 were enrolled in this study. Patients were divided into the MS and non-MS groups according to the presence of MS. The non-MS group included 70 patients, of whom 33 were females and 37 were males, and the mean age was $61.3 \pm 12.1$ years. The MS group included 80 patients, of whom 39 were females and 41 were males, and the mean age was $62.4 \pm 10.4$ years (Table I). There was no significant difference between the two groups regarding parameters such as age, sex, course of disease, BMI and other factors (Table I, $\mathrm{p}>0.05$ ). Patients in the MS group were divided into the normal and abnormal groups according to the levels of blood glucose, blood lipids and blood pressure. All normal groups were referred to as group A, and abnormal groups were referred to as group B. Different types of radical gastrectomy were performed for different patients according to their conditions. Inclusion criteria were: All enrolled patients were diagnosed with gastric cancer by gastroscopy and biopsy before surgery, and MS was diagnosed according to the diagnostic criteria of MS proposed by the Chinese Medical Association Diabetes Branch (10).

Patients who met three or all of the criteria of the following four items were diagnosed as MS: i) Overweight and (or) obesity $\mathrm{BMI} \geq 25.0$; ii) hyperglycemia: $\mathrm{FDG} \geq 6.1 \mathrm{mmol} / \mathrm{l}$ and (or) $2 \mathrm{hPG} \geq 7.8 \mathrm{mmol} / \mathrm{l}$ and (or) patients diagnosed with diabetes and received treatment; iii) hypertension: $\mathrm{SBP} / \mathrm{DBP} \geq 140$ and (or) has been diagnosed with hypertension and received treatment; and iv) dyslipidemia: Fasting blood $\mathrm{TG} \geq 1.7 \mathrm{mmol} / 1$. Exclusion criteria were: Severe cardiovascular and cerebrovascular diseases, renal failure, digestive system inflammation and mental disorders. This study was approved by the Ethics Committee of Daqing Longnan Hospital and all patients signed informed consent.

Research methods. Patients in the MS group were given corresponding drugs to control blood pressure, blood lipids and blood glucose, while patients in non-MS group were not

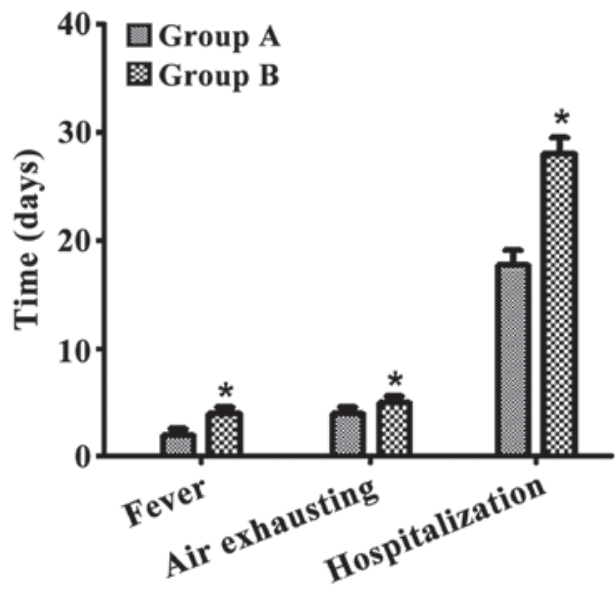

Figure 1. Comparison of durations of fever, air exhausting and hospitalization between the two groups. Durations of fever, air exhausting and hospitalization were significantly shorter in group A than in group B $\left({ }^{*} \mathrm{p}<0.05\right)$

treated with those drugs. Blood glucose, blood lipids, blood pressure, BMI, postoperative complications and recovery conditions of the two groups were recorded at 1 day before operation, and 1 and 3 months after operation.

Control standards. Patients in the MS group were treated with medication to control blood sugar, blood lipids and blood pressure after surgery. Specific requirements were as follows:

Postoperative blood glucose was controlled according to the recommended standards of the American Diabetes Association (2009) (11): i) $\mathrm{FBG} \leq 7.0 \mathrm{mmol} / 1,2 \mathrm{hPG} \leq 10 \mathrm{mmol} / \mathrm{l}$, HbAlc $\leq 6.5 \%$; and ii) FBG or $2 \mathrm{hPG}$ decrease $>1.39 \mathrm{mmol} / \mathrm{l}$ or HbAlc decrease $>1 \%$.

Postoperative blood glucose control: Outcomes met at least one of the three criteria referred to as effective blood glucose control: i) TGs, total cholesterol and LDL decreased by $>30 \%$; ii) high-density lipoprotein (HDL) increased by $>30 \%$; and iii) blood lipids reached below-normal levels.

Postoperative blood pressure control: Outcomes met at least one of the three criteria referred to as effective blood pressure control: SBP or DBP dropped by $>10 \mathrm{mmHg}$ $(1 \mathrm{mmHg}=0.133 \mathrm{kPa})$ or reached below normal $(140 / 90 \mathrm{mmHg})$ levels.

Statistical analysis. SPSS 17.0 statistical software (SPSS Inc., Chicago, IL, USA) was used for statistical analysis. Measurement data were expressed as mean $\pm \mathrm{SD}$, and paired t-test was used for comparisons within the two groups. In addition, count data were expressed as percentage and comparisons were performed by the $\chi^{2}$ test. Finally, logistic regression analysis was performed to analyze the correlations between postoperative complications and blood glucose, blood lipids and blood pressure. $\mathrm{P}<0.05$ was considered to be statistically significant.

\section{Results}

Comparison of blood glucose, blood lipids and blood pressure between the MS and non-MS groups before and at 1 month after surgery. Blood glucose, blood lipids and blood pressure 
Table I. General information of the MS and non-MS groups.

\begin{tabular}{|c|c|c|c|c|c|}
\hline Groups & Cases & Age (years) & $\begin{array}{c}\text { Sex ratio } \\
\text { (male/female) }\end{array}$ & $\begin{array}{c}\text { Course of } \\
\text { disease (months) }\end{array}$ & BMI $\left(\mathrm{kg} / \mathrm{m}^{2}\right)$ \\
\hline MS group & 80 & $62.4 \pm 10.4$ & 1.12 & $11.9 \pm 2.4$ & $24.2 \pm 4.3$ \\
\hline Non-MS group & 70 & $61.3 \pm 12.1$ & 1.05 & $11.4 \pm 2.1$ & $24.7 \pm 5.1$ \\
\hline P-value & & 0.521 & 0.143 & 0.243 & 0.211 \\
\hline
\end{tabular}

MS, metabolic syndrome.

Table II. Comparison of blood glucose, blood lipids and blood pressure between the MS and non-MS groups before and at 1 month after surgery mean \pm SD.

\begin{tabular}{lccccc}
\hline & \multicolumn{2}{c}{ MS group } & & \multicolumn{2}{c}{ Non-MS group } \\
\cline { 2 - 3 } \cline { 5 - 6 } Items & Before treatment & 1 month after treatment & & Before treatment & 1 month after treatment \\
\hline Blood glucose $(\mathrm{mmol} / \mathrm{l})$ & $11.32 \pm 3.21$ & $8.1 \pm 3.5^{\mathrm{a}}$ & & $7.2 \pm 2.5^{\mathrm{b}}$ & $7.8 \pm 3.1$ \\
SBP & $151.3 \pm 9.7$ & $132.5 \pm 8.9^{\mathrm{a}}$ & & $128.9 \pm 10.4^{\mathrm{b}}$ & $130.4 \pm 9.4$ \\
DBP & $98.5 \pm 8.7$ & $89.32 \pm 9.5^{\mathrm{a}}$ & & $85.5 \pm 8.6^{\mathrm{b}}$ & $89.43 \pm 7.4$ \\
BMI $\left(\mathrm{kg} / \mathrm{m}^{2}\right)$ & $24.2 \pm 4.3$ & $20.16 \pm 1.22^{\mathrm{a}}$ & & $24.7 \pm 5.1$ & $23.15 \pm 1.06$ \\
Total TGs $(\mathrm{mmol} / \mathrm{l})$ & $2.85 \pm 1.05$ & $1.92 \pm 0.65^{\mathrm{a}}$ & & $1.70 \pm 1.25^{\mathrm{b}}$ & $1.81 \pm 0.55$ \\
Total cholesterol (mmol/l) & $5.51 \pm 1.65$ & $3.82 \pm 1.42^{\mathrm{a}}$ & & $3.01 \pm 1.45^{\mathrm{b}}$ & $3.32 \pm 1.23$ \\
\hline
\end{tabular}

${ }^{\mathrm{a}}$ Comparisons within the two groups, $\mathrm{p}<0.05$; ${ }^{\mathrm{b}}$ comparisons between the two groups at the same time-point, $\mathrm{p}<0.05$. MS, metabolic syndrome; TGs, triglycerides.

Table III. Effects of blood glucose, blood lipids and blood pressure control on the occurrence of postoperative complications at 3 months after surgery $(\mathrm{n}, \%)$.

Blood pressure

Blood glucose

Blood lipids

Variables

Normal ( $\mathrm{n}=51)$ Abnormal $(\mathrm{n}=29)$ Normal $(\mathrm{n}=48)$ Abnormal $(\mathrm{n}=32)$ Normal $(\mathrm{n}=53)$ Abnormal $(\mathrm{n}=27)$

\begin{tabular}{lcc} 
Incision infection & 1 & 0 \\
Incision rupture & 0 & 2 \\
Abdominal infection & 0 & 2 \\
Lung infection & 0 & 1 \\
Anastomotic fistula & 1 & 3 \\
Pancreatic fistula & 1 & 3 \\
Delayed emptying & 1 & \multicolumn{2}{c}{1} \\
Deep vein thrombosis & 1 & \multicolumn{2}{c}{$14(48.3)$} \\
Total incidence & $5(9.8)$ & \multicolumn{2}{c}{35.958} \\
$\chi^{2}$ & \multicolumn{2}{c}{$<0.001$} \\
P-value & \multicolumn{2}{c}{}
\end{tabular}

\begin{tabular}{ccc}
2 & 2 \\
1 & 2 \\
0 & 2 \\
1 & 2 \\
0 & 2 \\
0 & 0 \\
0 & 1 \\
1 & 2 \\
$5(10.4)$ & $13(40.6)$ \\
\multicolumn{2}{c}{24.004} \\
& $<0.001$
\end{tabular}

\begin{tabular}{|c|c|}
\hline 1 & 1 \\
\hline 0 & 3 \\
\hline 0 & 1 \\
\hline 0 & 1 \\
\hline 1 & 2 \\
\hline 1 & 1 \\
\hline 0 & 0 \\
\hline 1 & 1 \\
\hline $4(7.5)$ & $10(37)$ \\
\hline \multicolumn{2}{|c|}{05152} \\
\hline & \\
\hline
\end{tabular}

levels were significantly higher in the MS group than in the non-MS group before and at 1 month after surgery $(\mathrm{p}<0.05)$. Compared to pre-treatment levels, blood glucose, blood lipids and blood pressure in the MS group dropped significantly at 1 month after surgery $(\mathrm{p}<0.05)$ (Table II).

Effects ofblood glucose, blood lipids andblood pressure control on the occurrence of postoperative complications at 3 months after surgery. Incidence of postoperative complications in patients with normal blood glucose, blood lipids and blood pressure in the MS group was significantly lower than that in patients with abnormal blood glucose, blood lipids and blood pressure (Table III).

Comparison of postoperative recovery between the normal groups (group A) and corresponding abnormal groups 
Table IV. Comparison of postoperative complications between groups A and B at 1 and 3 months after surgery (n, \%).

\begin{tabular}{|c|c|c|c|c|}
\hline \multirow[b]{2}{*}{ Complications } & \multicolumn{2}{|c|}{1 month after surgery } & \multicolumn{2}{|c|}{3 months after surgery } \\
\hline & Group A $(n=22)$ & Group B $(\mathrm{n}=58)$ & Group A $(n=22)$ & Group B $(n=58)$ \\
\hline Intestinal obstruction & $1(4.5)$ & $3(5.2)$ & $2(9)$ & $5(8.6)$ \\
\hline Ascites & $1(4.5)$ & $3(5.2)$ & $2(9)$ & $4(6.8)$ \\
\hline Pleural effusion & $0(0)$ & $2(3.4)$ & $1(4.5)$ & $2(3.4)$ \\
\hline Anastomotic fistula & $1(4.5)$ & $4(6.8)$ & $1(4.5)$ & $4(6.8)$ \\
\hline Incision infection & $0(0)$ & $3(5.2)$ & $0(0)$ & $5(8.6)$ \\
\hline Incision rupture & $0(0)$ & $3(5.2)$ & $0(0)$ & $5(8.6)$ \\
\hline Total incidence & $3(13.6)$ & $18(31)$ & $6(27.3)$ & $25(43.1)$ \\
\hline$\chi^{2}$ & \multicolumn{2}{|c|}{8.737} & \multicolumn{2}{|c|}{5.472} \\
\hline P-value & \multicolumn{2}{|c|}{0.003} & \multicolumn{2}{|c|}{0.019} \\
\hline
\end{tabular}

Table V. Value assignment of blood glucose, blood lipids, blood pressure and other related factors.

\begin{tabular}{lll}
\hline Serial no. & \multicolumn{1}{c}{ Items } & \multicolumn{1}{c}{ Value assignment } \\
\hline 1 & FBG & $\geq 0 ;$ male, 1 \\
2 & 2 h postprandial blood glucose & $<7.8 \mathrm{mmol} / 1,0 ; \geq 7.8 \mathrm{mmol} / \mathrm{l}, 1$ \\
3 & Glycated hemoglobin & $<6.1,0 ; \geq 6.1,1$ \\
4 & Total TGs & $<1.7 \mathrm{mmol} / 1,0 ; \geq 1.7 \mathrm{mmol} / 1,1$ \\
5 & LDL & $>0.9 \mathrm{mmol} / 1,0 ; \leq 0.9 \mathrm{mmol} / 1,1$ \\
6 & Average blood pressure & $\mathrm{SBP} / \mathrm{DBP}<140 / 90 \mathrm{mmHg}, 0 ; \mathrm{SBP} / \mathrm{DBP} \geq 140 / 90 \mathrm{mmHg}, 1$ \\
7 & BMI & $<25,0 ; \geq 25,1$
\end{tabular}

TGs, triglycerides.

Table VI. Correlations between the postoperative complications and blood glucose, blood lipids and blood pressure by logistic regression analysis.

\begin{tabular}{lccccc}
\hline $\begin{array}{l}\text { Observation } \\
\text { indexes }\end{array}$ & $\begin{array}{c}\text { Partial regression } \\
\text { coefficient }\end{array}$ & $\begin{array}{c}\text { Partial regression } \\
\text { coefficient standard error }\end{array}$ & $\begin{array}{c}\text { Wald } \chi^{2} \\
\text { value }\end{array}$ & P-value & OR (95\% CI) \\
\hline $\begin{array}{l}\text { Fasting blood sugar } \\
\text { h postprandial blood }\end{array}$ & 1.344 & 0.336 & 15.977 & $<0.001$ & $3.834(1.984-7.411)$ \\
glucose & 0.783 & 0.443 & 8.126 & 0.037 & $2.189(6.918-10.215)$ \\
Glycated hemoglobin & 0.644 & 0.336 & 3.906 & 0.048 & $1.942(1.006-3.752)$ \\
Total TGs & 0.468 & 0.274 & 2.916 & 0.088 & $1.596(0.93-2.730)$ \\
HDL & 0.436 & 0.327 & 7.223 & 0.040 & $1.515(6.814-8.941)$ \\
Average blood pressure & 0.345 & 0.127 & 9.306 & 0.035 & $1.485(7.912-12.540)$ \\
BMI & 0.012 & 0.007 & 3.943 & 0.045 & $1.358(1.065-1.650)$ \\
\hline
\end{tabular}

TGs, triglycerides; HDL, high-density lipoprotein.

(group B). The incidence of postoperative complications was significantly lower in group A than in group B $(p<0.05$; Table IV). Furthermore, postoperative recovery was significantly better in group A than in the corresponding group B ( $<<0.05$, Fig. 1).
Correlations between postoperative complications and blood glucose, blood lipids and blood pressure by logistic regression analysis. Logistic regression analysis showed that the incidence of postoperative complications was associated with fasting blood glucose, $2 \mathrm{~h}$ postprandial blood glucose, 
glycosylated hemoglobin, LDL, mean blood pressure and BMI $(\mathrm{p}<0.05)$ (Tables V and VI).

\section{Discussion}

The incidence and mortality rate of gastric cancer are relatively high in China. The mortality rate of gastric cancer is affected by regional factors and sex, and is higher in males than in females (12). The cure rate of gastric cancer at an early stage is relatively high, but most patients with gastric cancer are diagnosed at advanced stages due to lack of manifestations at early stages (13). MS is a group of metabolic disorders characterized by IR, including obesity, hyperglycemia, hypertension and dyslipidemia (14). Reynolds and He (15) reported that the incidence of MS was $19.5 \%$ in adults and $18 \%$ in women. MS is closely associated with the occurrence and development of various malignant tumors, especially gastrointestinal tumors, most commonly colorectal, liver and gastric cancer. In addition, Corley et al (16) have shown that diabetes is a risk factor for gastric cancer. Metabolic abnormalities can promote the occurrence and development of cancer, and dyslipidemia is closely associated with the occurrence of gastric cancer (17). The 5-year survival rate of cancer patients complicated with MS who underwent blood pressure and blood glucose control was significantly higher than that of those without proper blood pressure and blood glucose control (18). This study showed that the proper use of drugs for 1 month led to a decrease of blood pressure, blood lipids and blood glucose control to normal levels in the MS group, and there was no statistical difference between the MS and non-MS groups. In addition, the incidence of postoperative complications was significantly lower, while recovery conditions were significantly better in patients with normal blood pressure, blood lipids and blood glucose than that of patients with abnormal blood pressure, blood lipids and blood glucose at 1 and 3 months after surgery.

Wang et al (19) have shown that preoperative correction and improvement of certain medical factors in patients can reduce the incidence of complications to some extent. A body's stress response caused by surgical stimulation can cause IR in patients, which in turn affects the level of insulin and cause fluctuations of blood glucose, resulting in the occurrence of related complications. For MS patients, blood glucose, blood lipids and blood pressure should be controlled by using corresponding drugs after surgery to improve dyslipidemia. Compared with other risk factors, MS and its related factors have less controllability and are prone to fluctuate during the perioperative period, making them more prominent in occurrence of postoperative complications of gastric cancer patients. In this study, logistic regression analysis showed that incidence of postoperative complications was related to fasting blood glucose, $2 \mathrm{~h}$ postprandial blood glucose, glycosylated hemoglobin, total TGs, LDL, mean blood pressure and BMI $(\mathrm{p}<0.05)$. These findings are consistent with those reported by Kim et al (20) that patients with hyperglycemia, hypertension, and hyperlipidemia had a significantly higher probability of developing adverse reactions than non-MS patients, and BMI was in direct proportion to the incidence of hyperlipidemia.

In conclusion, effective control of blood glucose, blood lipid and blood pressure in patients with gastric cancer complicated with MS after radical gastrectomy can reduce the incidence of postoperative complications and promote postoperative recovery.

\section{Acknowledgements}

Not applicable.

\section{Funding}

No funding was received.

\section{Availability of data and materials}

The datasets used and/or analyzed during the present study are available from the corresponding author on reasonable request.

\section{Authors' contributions}

LS was a major contributor in writing this manuscript and patient treatment. PZ collected the data. QH analysed the data. CJ provided ideas on methods and interpreted the results. CG designed this study and performed the research. BS revised and finalized this report. All authors read and approved the final manuscript.

\section{Ethics approval and consent to participate}

This study was approved by the Ethics Committee of Daqing Longnan Hospital (Daqing, China). The patients who participated in this study, signed informed consent and had complete clinical data.

\section{Consent for publication}

Not applicable.

\section{Competing interests}

The authors declare that they have no competing interests.

\section{References}

1. Hartgrink HH, Jansen EPM, van Grieken NCT and van de Velde CJH: Gastric cancer. Lancet 374: 477-490, 2009.

2. Catalano V, Labianca R, Beretta GD, Gatta G, de Braud F and Van Cutsem E: Gastric cancer. Crit Rev Oncol Hematol 71: 127-164, 2009.

3. Baghestani AR, Daneshva T, Pourhoseingholi MA and Asadzadeh H: Survival of colorectal cancer in the presence of competing-risks-modeling by Weibull distribution. Asian Pac J Cancer Prev 17: 1193-1196, 2016.

4. Hu D, Peng F, Lin X, Chen G, Zhang H, Liang B, Ji K, Lin J, Chen LF, Zheng X, et al: Preoperative metabolic syndrome is predictive of significant gastric cancer mortality after gastrectomy: The Fujian Prospective Investigation of Cancer (FIESTA) Study. EBioMedicine 15: 73-80, 2017.

5. Bloomgarden ZT: Obesity and diabetes. Diabetes Care 23: 1584-1590, 2000.

6. Katzmarzyk PT, Janssen I, Ross R, Church TS and Blair SN: The importance of waist circumference in the definition of metabolic syndrome: Prospective analyses of mortality in men. Diabetes Care 29: 404-409, 2006.

7. Lin Y, Ness-Jensen E, Hveem K, Lagergren J and Lu Y: Metabolic syndrome and esophageal and gastric cancer. Cancer Causes Control 26: 1825-1834, 2015. 
8. Peng F, Hu D, Lin X, Chen G, Liang B, Zhang H, Ji K, Huang J, Lin J, Zheng X, et al: Preoperative metabolic syndrome and prognosis after radical resection for colorectal cancer: The Fujian prospective investigation of cancer (FIESTA) study. Int J Cancer 139: 2705-2713, 2016.

9. Sasako M, Sano T, Yamamoto S, Kurokawa Y, Nashimoto A, Kurita A, Hiratsuka M, Tsujinaka T, Kinoshita T, Arai K, et al Japan Clinical Oncology Group: D2 lymphadenectomy alone or with para-aortic nodal dissection for gastric cancer. N Engl J Med 359: 453-462, 2008.

10. Biesen R, Burmester GR and Hiepe F: Rheumatoid factor or antinuclear antibodies as incidental finding. Internist (Berl) 55: 1157-1164, 2014 (In German).

11. Pourhoseingholi MA, Moghimi-Dehkordi B, Safaee A, Hajizadeh E, Solhpour A and Zali MR: Prognostic factors in gastric cancer using log-normal censored regression model. Indian J Med Res 129: 262-267, 2009.

12. Won KB, Chang HJ, Han D, Sung J and Choi SY: Metabolic syndrome predicts long-term mortality in subjects without established diabetes mellitus in asymptomatic Korean population: A propensity score matching analysis from the Korea Initiatives on Coronary Artery Calcification (KOICA) registry. Medicine (Baltimore) 95: e5421, 2016.

13. Esposito K, Chiodini P, Colao A, Lenzi A and Giugliano D: Metabolic syndrome and risk of cancer: A systematic review and meta-analysis. Diabetes Care 35: 2402-2411, 2012.

14. Zhou HC, Lai YX, Shan ZY, Jia WP, Yang WY, Lu JM, Weng JP, Ji LN, Liu J, Tian HM, et al: Effectiveness of different waist circumference cut-off values in predicting metabolic syndrome prevalence and risk factors in adults in China. Biomed Environ Sci 27: 325-334, 2014.
15. Reynolds K and He J: Epidemiology of the metabolic syndrome. Am J Med Sci 330: 273-279, 2005.

16. Corley DA, Kubo A and Zhao W: Abdominal obesity and the risk of esophageal and gastric cardia carcinomas. Cancer Epidemiol Biomarkers Prev 17: 352-358, 2008.

17. MacInnis RJ, English DR, Hopper JL and Giles GG: Body size and composition and the risk of gastric and oesophageal adenocarcinoma. Int J Cancer 118: 2628-2631, 2006.

18. Lee S, Bacha F and Arslanian SA: Waist circumference, blood pressure, and lipid components of the metabolic syndrome. J Pediatr 149: 809-816, 2006.

19. Wang H, Zhou XB, Zhou YB, Niu ZJ, Chen D, Wang DS, Lü L and Li Y: Multivariate logistic regression analysis of postoperative severe complications and discriminant model establishment in gastric cancer post gastrectomy. Zhonghua Wai Ke Za Zhi 46: 1902-1905, 2008 (In Chinese).

20. Kim HA, Jeon JY, An JM, Koh BR and Suh CH: C-reactive protein is a more sensitive and specific marker for diagnosing bacterial infections in systemic lupus erythematosus compared to S100A8/A9 and procalcitonin. J Rheumatol 39: 728-734, 2012.

This work is licensed under a Creative Commons Attribution-NonCommercial-NoDerivatives 4.0 International (CC BY-NC-ND 4.0) License. 